\title{
Hypoglossal-facial nerve anastomosis: a clinical and electrophysiological follow-up
}

\author{
ROBERT IANSEK, MICHAEL JG HARRISON, JOHN ANDREW \\ From the Departments of Neurology and Neurosurgery, The Middlesex Hospital, London
}

SUMMARY Eight patients with acoustic neuroma and five patients with hemifacial spasm, who had undergone hypoglossal-facial nerve anastomosis 1-14 years previously, were reviewed clinically and electrophysiologically with an electrically elicited blink reflex. Functional recovery from the anastomosis, as rigorously judged on a scale of good, fair and poor, was fair to poor. Electrically it was found that the blink reflex was present in eight patients, suggesting facial nerve re-innervation of the facial musculature. This was confirmed by the mild recurrence of hemifacial spasm in four patients. Implications for the future role of this operative procedure are discussed.

Hypoglossal-facial nerve anastomosis is an uncommon procedure usually performed for unresolved facial palsy following surgery for acoustic neuroma or, more rarely, for relief of hemifacial spasm. Few reports ${ }^{12}$ have looked at the long term results of such surgery and no electrophysiological assessment of the anastomosis has been published. We were interested in the latter problem as several patients appeared to have a recurrence of hemifacial spasm despite evidence of adequate hypoglossal-facial nerve anastomosis. ${ }^{3}$ We suspected clinically that the facial nerve may have re-innervated the facial muscles by growth into the anastomosis. We tested this hypothesis by the performance of the blink reflex in all patients to assess facial re-innervation by the facial nerve.

\section{Method}

Patients who had had hypoglossal-facial nerve anastomosis performed by one us (JA) between 1970 and 1983 were contacted by post. The respondents were reviewed clinically and electrophysiologically. Clinical assessment consisted of subjective response to problems with corneal cover, chewing, swallowing and with facial appearance. Objective assessment consisted of the determination of the presence of facial symmetry at rest, for eye closure, smiling and for eyebrow elevation and the assessment of mass action on tongue

Address for reprint requests: Dr R Iansek, Prince Henry's Hospital, St Kilda Road, Melbourne, Victoria 3004, Australia

Received 23 July 1985 and in revised form 12 October 1985. Accepted 16 October 1985 movement. The results of clinical evaluation were classified as good, fair and poor according to previously published criteria. $^{12}$ These criteria were as follows: a good result was when the patient gained facial symmetry at rest, complete voluntary eye closure, voluntary movement of the corner of the mouth and no significant inconvenience from the anastomosis. A fair result consisted of incomplete facial symmetry at rest and incomplete eye closure with poor voluntary movements. A poor result consisted of gross facial asymmetry at rest, insufficient eye closure to protect the cornea, no voluntary movements and significant disability from loss of hypoglossal function. The blink reflex was performed according to the technique described by Kimura. ${ }^{4}$

\section{Results}

A total of 13 patients were available for follow up. Follow up time from operation to review varied from 1 to 14 years. The main complaints patients had in relation to corneal cover were with difficulties in the wind or heat, when the eye would get gritty and uncomfortable. Seven patients complained of these symptoms. One patient still had a tarsorrhaphy in situ at the time of review. Chewing difficulties were present in eight patients and these consisted of difficulty in moving the food around the mouth, inability to chew on the affected side, dribbling and difficulty getting the food to the back of the throat. Six patients described difficulty in swallowing and this related to the initiation of deglutition and also to food sticking in the back of the throat and in the requirement of several attempts to initiate swallowing. Six 
Table Summary of blink reflex responses in all patients who had undergone previous hypoglossal-facial nerve anastomosis

\begin{tabular}{|c|c|c|c|c|c|c|c|}
\hline \multirow[t]{2}{*}{ Patient } & \multirow[t]{2}{*}{ Aetiology } & \multicolumn{3}{|c|}{ Operated side ms } & \multicolumn{3}{|c|}{ Unoperated side ms } \\
\hline & & $R I$ & $R 2$ & $R C 2$ & $R I$ & $R 2$ & $R C 2$ \\
\hline $\begin{array}{r}1 \\
2 \\
3 \\
4 \\
5 \\
6 \\
7 \\
8 \\
9 \\
10 \\
11 \\
12 \\
13\end{array}$ & $\begin{array}{l}\text { Acoustic } \\
\text { Acoustic } \\
\text { Acoustic } \\
\text { Acoustic } \\
\text { Acoustic } \\
\text { Acoustic } \\
\text { Acoustic } \\
\text { Acoustic } \\
\text { HFS* } \\
\text { HFS* } \\
\text { HFS } \\
\text { HFS* } \\
\text { HFS* }\end{array}$ & $\begin{array}{l}\overline{\bar{T}} \\
\overline{14} \cdot 6 \\
10 \cdot 0 \\
14 \cdot 0 \\
\overline{12} \cdot 3 \\
12 \cdot 4 \\
15 \cdot 6 \\
\overline{11} \cdot 0 \\
11.9\end{array}$ & $\begin{array}{l}\overline{-} \\
\overline{34} \cdot 4 \\
\overline{36} \cdot 0 \\
63 \cdot 0 \\
\overline{-} \\
\overline{39 \cdot 0} \\
30 \cdot 4 \\
56 \cdot 0 \\
34 \cdot 0\end{array}$ & $\begin{array}{l}35.6 \\
32.0 \\
34.7 \\
35.0 \\
26.0 \\
37.0 \\
43.0 \\
47.0 \\
37.0 \\
31.4 \\
37.0 \\
30.0 \\
28.4\end{array}$ & $\begin{array}{r}12.5 \\
12.1 \\
10.5 \\
13.0 \\
9.0 \\
10.0 \\
10.0 \\
11.4 \\
10.0 \\
11.0 \\
11.0 \\
10.0 \\
9.2\end{array}$ & $\begin{array}{l}35 \cdot 5 \\
33 \cdot 0 \\
34 \cdot 0 \\
38 \cdot 0 \\
28 \cdot 0 \\
38.0 \\
40.0 \\
37.0 \\
33 \cdot 0 \\
34.0 \\
40.0 \\
32.0 \\
29 \cdot 0\end{array}$ & $\begin{array}{l}\bar{Z} \\
\overline{31} \cdot 4 \\
\overline{31} \cdot 0 \\
67 \cdot 0 \\
\overline{-} \\
\overline{40.0} \\
35 \cdot 0 \\
50 \cdot 0 \\
31 \cdot 0\end{array}$ \\
\hline
\end{tabular}

The asterisk (*) identifies patients who experienced return of hemifacial spasm.

R1 early direct response (normal $8-13 \mathrm{~ms}){ }^{4}$

R2 late direct response (normal $21-41 \mathrm{~ms}$ ). ${ }^{4}$

RC2 late consensual response (normal $18-44 \mathrm{~ms}){ }^{4}$

HFS $=$ hemifacial spasm.

patients were unhappy about their facial appearance, particularly when eating; so much so that these patients disliked eating in public. This complaint related to the mass action produced on tongue movements during chewing.

Examination revealed facial symmetry at rest in six patients. Eye closure was complete in only one patient. All other patients were able to cover the cornea but not the lower sclera. Pushing the tongue to the roof of the mouth would produce complete, but not forceful eye closure. Unfortunately, all patients denied active use of tongue movements for purposeful facial movement. No patient had facial symmetry for the lower part of the face when smiling; two patients having only minor movement at the angle of the mouth. One patient had minimal movement on eyebrow elevation; the remainder of the subjects had no voluntary movement. The majority (11) of patients were troubled by mass movement of the side of the face when the tongue was pressed to the roof of the mouth and this was most obvious during conversation or when chewing.

The summarised results of the blink reflex are shown in the table. The blink reflex was present on the operated side either completely (3) or incompletely (2) in all patients with hemifacial spasm. The $R 1$ direct response was slowed in three patients consistent with the re-anastomosis of the facial nerve. The R2 response was delayed only in the patient with an absent $R 1$ response. This finding would be consistent with brain stem slowing of conduction rather than the initial severance of the facial nerve distally. ${ }^{56}$ Similarly, the absent $\mathbf{R} 2$ response in another patient is also consistent with such a conclusion. Four patients had a recurrence of hemifacial spasm at review. These patients are marked with an asterisk in the table. They all had obvious twitching around the affected eye although to a mild degree as compared to the preoperative state. The same patients also had return of either partial or complete blink reflex response pattern. In the acoustic neuroma group, four patients had return of blink reflex responses. Two patients had a delayed $R 1$ component consistent with a slowing of conduction along the facial nerve through the anastomosis. The remaining two patients had a normal R1 response. One patient had only an $\mathrm{R} 1$ response.

\section{Discussion}

The results of our clinical follow up of patients with hypoglossal-facial nerve anastomosis were generally fair to poor as judged on previously described criteria. ${ }^{12}$ The best results were for six patients who had facial symmetry at rest, yet none had complete voluntary eye closure and only two patients had some minor voluntary movement of the orbicularis oris muscle. Furthermore, these patients were troubled by mass action on tongue movement. Previous clinical reviews have had differing results at follow-up. A recent report ${ }^{1}$ of 12 patients showed a predominantly good response following anastomosis, whereas another report ${ }^{2}$ of five patients showed a fair to good response. The discrepancies between our findings and the previous reports may only be an indication of the small patient numbers involved in follow up, or it may reflect discrepancies in the characterisation of recovery. Our generally unsatisfactory results of hypoglossal-facial nerve anastomosis suggest to us that alternate operations should be considered for facial palsy following removal of acoustic neuroma. An antogenous nerve graft may produce better results by obviating partial loss of tongue function or mass action. Such an operation would also take advantage of the regrowth potential of the facial nerve as dem- 
onstrated by our finding of the presence of a blink reflex in some patients.

Recurrence of spasm at the time of review was present in four patients with previous hemifacial spasm. The degree of spasm was only minor and consisted of twitches around the eye. One patient required re-exploration and re-anastomosis because of the severity of the recurrence of spasm. ${ }^{3}$ Despite re-anastomosis an incomplete blink reflex response had returned at follow up.

Electrophysiologically the blink reflex had returned partially or fully in all patients with hemifacial spasm. This finding implied functional re-innervation of the facial musculature by the proximal stump of the facial nerve via the anastomosis. ${ }^{6}$ Such re-innervation is consistent with recurrence of spasm in these patients. The implication of this finding is that the proximal stump of the facial nerve should be kept well clear of the anastomosis if such an operation is attempted for hemifacial spasm. However, we would recommend alternative procedures for the treatment of hemifacial spasm as the recurrence rate was high and the results of hypoglossal-facial nerve anastomosis unsatisfactory. The results of the blink reflex in several patients suggested slowing within the brainstem. In the acoustic neuroma group this finding could be explained by either the mass effect of the tumour on the brainstem or as a consequence of the surgery. In the hemifacial spasm group, brainstem slowing could not be attributed to either of these explanations and it was concluded that the slowing was probably due to the underlying cause of the hemifacial spasm. A previous report ${ }^{7}$ has shown that the blink reflex responses are generally slowed on the side of the hemifacial spasm as compared with the normal side and as compared to the normal population. However, this study only published the mean and standard deviation for the blink reflex responses for the total population rather than detail the slowing characteristics in each patient, making it impossible to confirm our finding. This author ${ }^{7}$ suggested a peripheral cause for hemifacial spasm. However, a more recent report $^{8}$ outlined evidence of central rather than peripheral slowing of nerve conduction times in hemifacial spasm. This finding is in agreement with the finding of this report: that central slowing of the blink reflex components can occur in hemifacial spasm. The implication is that the cause of hemifacial spasm may sometimes be central rather than peripheral as postulated by previous investigations. $^{910}$

Financial assistance from Winthrop Pharmaceuticals is gratefully acknowledged by Robert Iansek.

\section{References}

${ }^{1}$ Chang CGS, Shen ALY. Hypoglossal-facial anastomosis for facial palsy after resection of acoustic neuroma. Surg Neurol 1984;21:281-6.

${ }^{2}$ Mingrino S, Zuccarrello M. Anastomosis of the facial nerve with accessory or hypoglossal nerves. In: Sammii M, Janetta PJ, eds. The Cranial Nerves. Heidelberg: Springer-Verlag, 1981:512-48.

${ }^{3}$ Harrison MJG, Andrew J. Recurrence of hemifacial spasm after hypoglossal-facial anastomosis. J Neurol Neurosurg Psychiatry 1981;44:558-9.

${ }^{4} \mathrm{Kimura} \mathrm{J}$. Electrically elicited blink reflex in the diagnosis of multiple sclerosis. Brain 1975;98:413-26.

${ }^{5}$ Kimura J, Lyon LW. Orbicularis oculi reflex in the Wallenberg syndrome. Alteration of the late reflex by lesions of the spinal tract and nucleus of the trigeminal nerve. J Neurol Neurosurg Psychiatry 1972;35:228-33.

${ }^{6}$ Kimura J. Electrodiagnosis in Diseases of Nerve and Muscle. Principles and Practice. Philadelphia, FA Davis, 1983.

${ }^{7}$ Nielson VK. Pathophysiology of hemifacial spasm: II. Lateral spread of the supra orbital nerve reflex. Neurology (Cleveland) 1984;34:427-31.

${ }^{8}$ Moller AR, Janetta PJ. On the origin of synkinesis in hemifacial spasm; results of intracranial recordings. $J$ Neurosurg 1984;61:569-76.

${ }^{9}$ Wartenberg R. Hemifacial spasm. A clinical and pathological study. New York: Oxford University Press, 1952.

${ }^{10}$ Janetta PJ. Surgical approach to hemifacial spasm: microvascular decompression. In: Marsden CD, Fahn S, eds. Movement Disorders. London, Butterworth, 1982:330-3. 